\title{
Traje de tradição: elementos da contemporaneidade na cultura de rua
}

Traditional costume: contemporary elements in street culture. 


\section{Traje de tradição: elementos da contemporaneidade na cultura de rua}

Traditional costume: contemporary elements in street culture.

\section{Márcia Merlo}

\section{Resumo}

$\mathrm{O}$ artigo discorre sobre a memória dos trajes e a maneira como os indivíduos registram e interpretam suas relações com eles. Parte-se do pressuposto de que nos colocamos em tudo e, por essa razão, também, os trajes populares revelam o lugar político de cada sujeito na Festa de São Benedito na Congada de Ilhabela manifestação da cultura afrodescendente escolhida para ser tratada neste texto. Objetivou-se entender o papel do traje na composição da identidade cultural do grupo étnico-racial negro de Ilhabela, para apontar como um traje aparentemente simples pode revelar tantos significados para o grupo em questão. A Congada de Ilhabela representa a devoção de uma população a um santo; santo e povo negro que resistiram aos inúmeros preconceitos e a transformações socioeconômicas profundas. Para tanto, será discutida a expressão dessa cultura como tradição inventada por meio de uma identidade negociada. No que concerne ao traje, o estudo se apoiará na cultura material e na observação participante realizada com essa população entre os anos de 1995 e 2002.

Palavras- chave: trajes, etnias, contemporaneidade.

\begin{abstract}
The article discusses the memory of the costumes and the way people record and interpret their relations with them. This is on the assumption that we put ourselves at all, and for that reason, too, the popular costumes reveal the political place of each subject on the Festa de São Benedito in Congada de Ilhabela - manifestation of African descent culture chosen to treated in this text. This study aimed to understand the role of costume in the composition of the cultural identity of black ethnic-racial group of Ilhabela, to point out how a seemingly simple costume can reveal so many meanings for the group in question. The Congada de Ilhabela is the devotion of a population to a saint; holy and black people who resisted the many prejudices and deep social and economic transformations. Therefore, the expression of that culture and tradition invented by means of a negotiated identity will be discussed. Regarding the costume, the study will be based on material culture and participant observation conducted with this population between the years 1995 to 2002.
\end{abstract}

Keywords: costumes, ethnic groups, contemporaneity. 


\section{Introdução}

A ideia que move este artigo parte de um projeto de pesquisa em torno do Design e da Cultura, focado no estudo da cultura material à luz de teorias antropológicas, da Memória e da História da Indumentária, do Design e da Moda. O tema perpassa a importância dos trajes de festas populares na recriação de identidades culturais.

Parte de estudos em torno da Indumentária promovidos pelo MIMo (Museu da Indumentária e da Moda), no que tange à memória dos trajes e à maneira como os indivíduos registram e interpretam suas relações com eles, uma vez que o foco está na observação e na análise do vestuário, comportamento e seu entorno, o que significa dizer que se encara a cultura como mote da discussão no campo do Design e da Moda. Isto porque os trajes são pensados como artefatos que contêm memórias, tornando-se contadores de histórias, em potencial. Por isso, observá-los e, também, relacioná-los à prática cultural a qual pertencem é pensar as intersecções possíveis entre sujeitos e objetos. O traje, no caso, é o veículo da identidade e, portanto, o marcador de um lugar social de um grupo étnico-cultural. Mais do que um pedaço de cetim barato confeccionado a partir de uma modelagem simples, o traje popular da Congada de Ilhabela é vestido por um sujeito que festeja o santo e se auto festeja, porque a história do santo e a sua, negro em Ilhabela, se misturam, interpenetram-se nas memórias e recriam identidades.

Figura 1: Rei Congo - Dito de Pilaca e ao seu lado a Rainha coroada para aquele ano. Ilhabela, Maio de 2014. Foto de Douglas Lopez. 


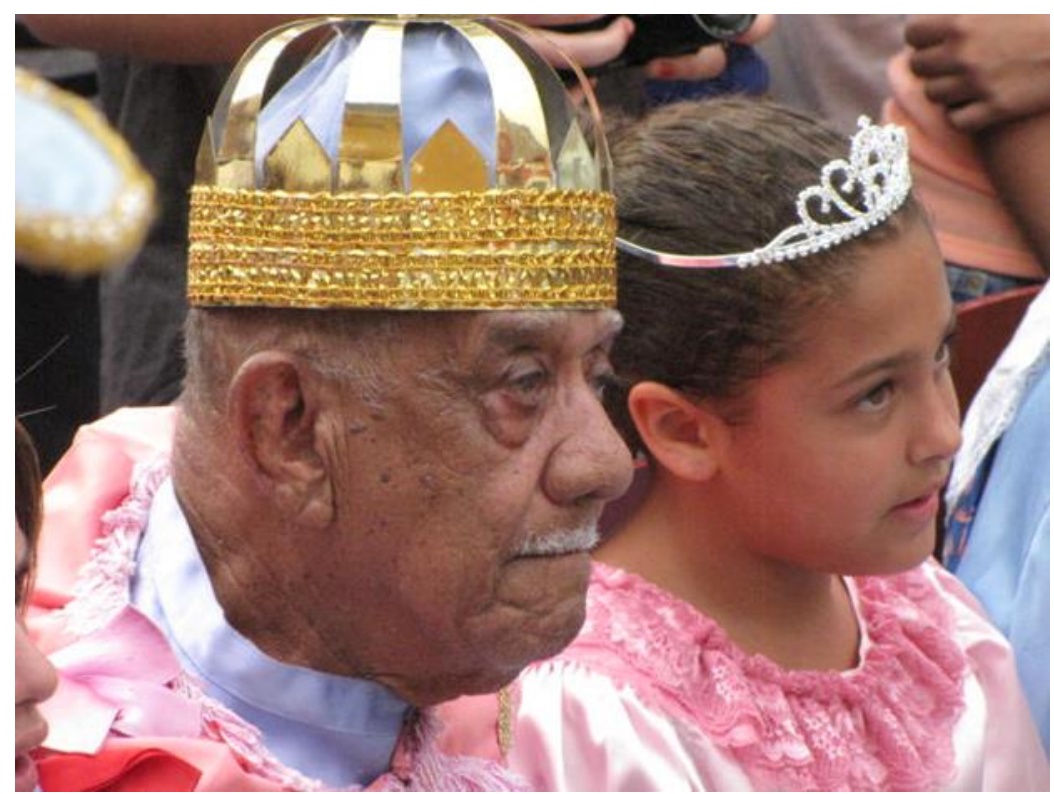

Fonte: Arquivo Pessoal.

Por se tratar de festas populares, faz-se necessário compreender os sentidos dos trajes, para direcionar o debate das construções simbólicas de grupos étnicos-culturais. Em Ilhabela, inicialmente, ouvi e li que os congueiros ${ }^{1}$ ocupavam as ruas "fantasiados" de trajes azuis e rosas "teatralizando" uma guerra em prol da catequização. O Rei Congo, convertido ao cristianismo, lutava contra os pagãos. Ao vencer a batalha, o Rei Congo e o Embaixador Mouro seguiam fazendo suas reverências ao santo católico. Em uma história cheia de surpresas, descobrimos ao final que o embaixador mouro era filho do Rei. Filho que sai de sua terra natal, mas, entre uma batalha e outra para conquistar um novo reino, reencontra o Pai. Ao vê-lo, ajoelha e senta ao lado do Rei, pacificando a batalha e unindo os lados. Todos viram devotos ao São Benedito.

Com o passar do tempo, pude compreender que a luta era pela manutenção da identidade africana, afrodescendente, afro-brasileira e o santo negro era a maior representação da inserção do grupo étnico-racial em Ilhabela.

\footnotetext{
1 Congueiro é o homem participante da Congada de Ilhabela que acontece no mês de maio em comemoração ao São Benedito, seu padroeiro. A mulher tem maior envolvimento na Ucharia que é a cozinha da Congada, junto aos homens que também participam do "fazimento" da comida para os congueiros e convidados. Também uma garota virgem é coroada para ser a rainha durante uma apresentação. Virgem para representar a pureza. A coroação da rainha é, também, um momento muito esperado no final de cada Festa. Durante o ano, todos se preparam para a próxima Congada. Os vestidos das rainhas são da responsabilidade da família. As roupas dos homens e crianças, hoje, são feitas pelas famílias dos congueiros e por elas devem ser conservadas, mas antes eram feitas por uma artesã, assim como os chapéus e as espadas, por um artesão. Em Ilhabela não há um Museu do Caiçara, ou uma Casa de Cultura que preserve os trajes dos congueiros, uma das maiores queixas dos participantes.
} 
Figura 2: A batalha - o Embaixador (pagão, veste vermelho) tenta chegar até o Rei Congo (católico, veste azul). Foto de Douglas Lopez.

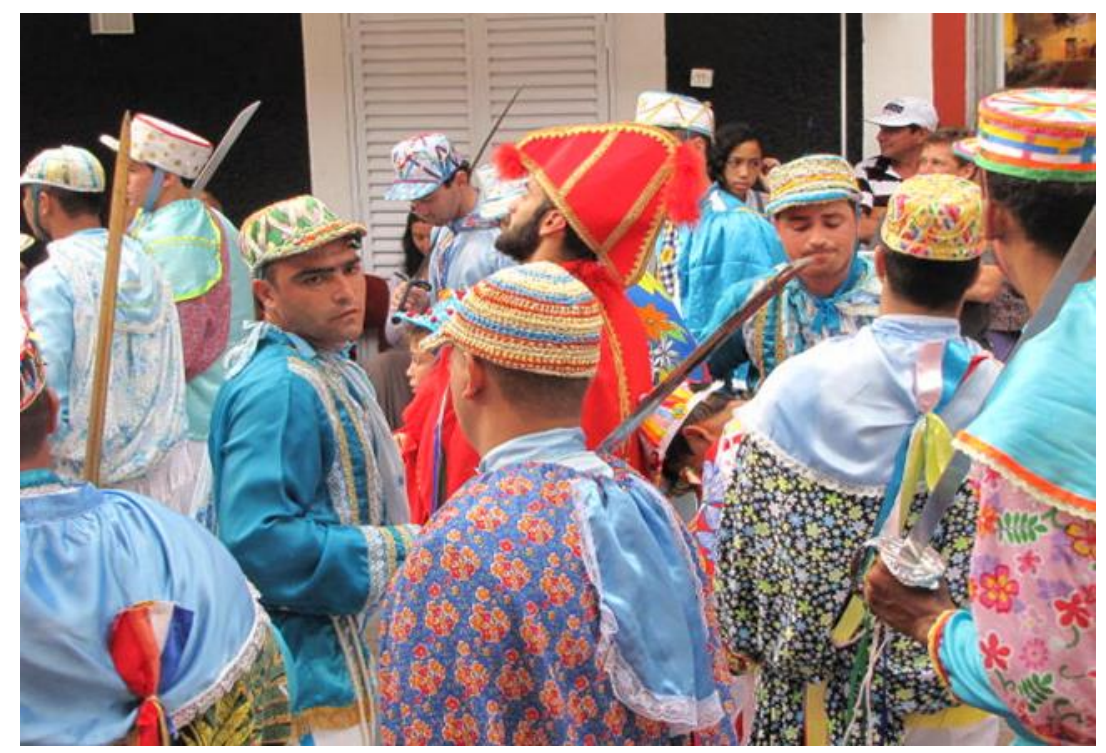

Fonte: Arquivo Pessoal. Maio de 2014.

Os trajes são pensados, portanto, como meios de se posicionar em uma sociedade abrangente e desigual. E também como elementos da atualidade que se inserem na tradição, sobretudo ao refletirem modos de ser, pensar, sentir, fazer. Ou, ainda, podemos entender como os trajes populares, dentro de manifestações que recriam identidades de grupos minoritários, assimilam novos elementos desde a sua composição até suas constantes reinvenções. Mesmo assim, não perdem os sentidos de outrora, porque, mais do que o traje, o sentimento ali depositado, a resistência de continuar, ano após ano, organizando a Festa e reverenciando o Santo, dá ao traje a mesma força que a fé dá ao grupo que o veste. E tudo ali acontece por devoção ao santo negro, para não desaparecer a crença, mas sobretudo para sobreviverem as (os) afrodescendentes. 
Figura 3: Em destaque, O Rei Congo Dinho, coroado em 2014 e o São Benedito, padroeiro da Congada de Ilhabela, em procissão nas ruas do Centro Histórico. Foto: Márcio Pannunzio.

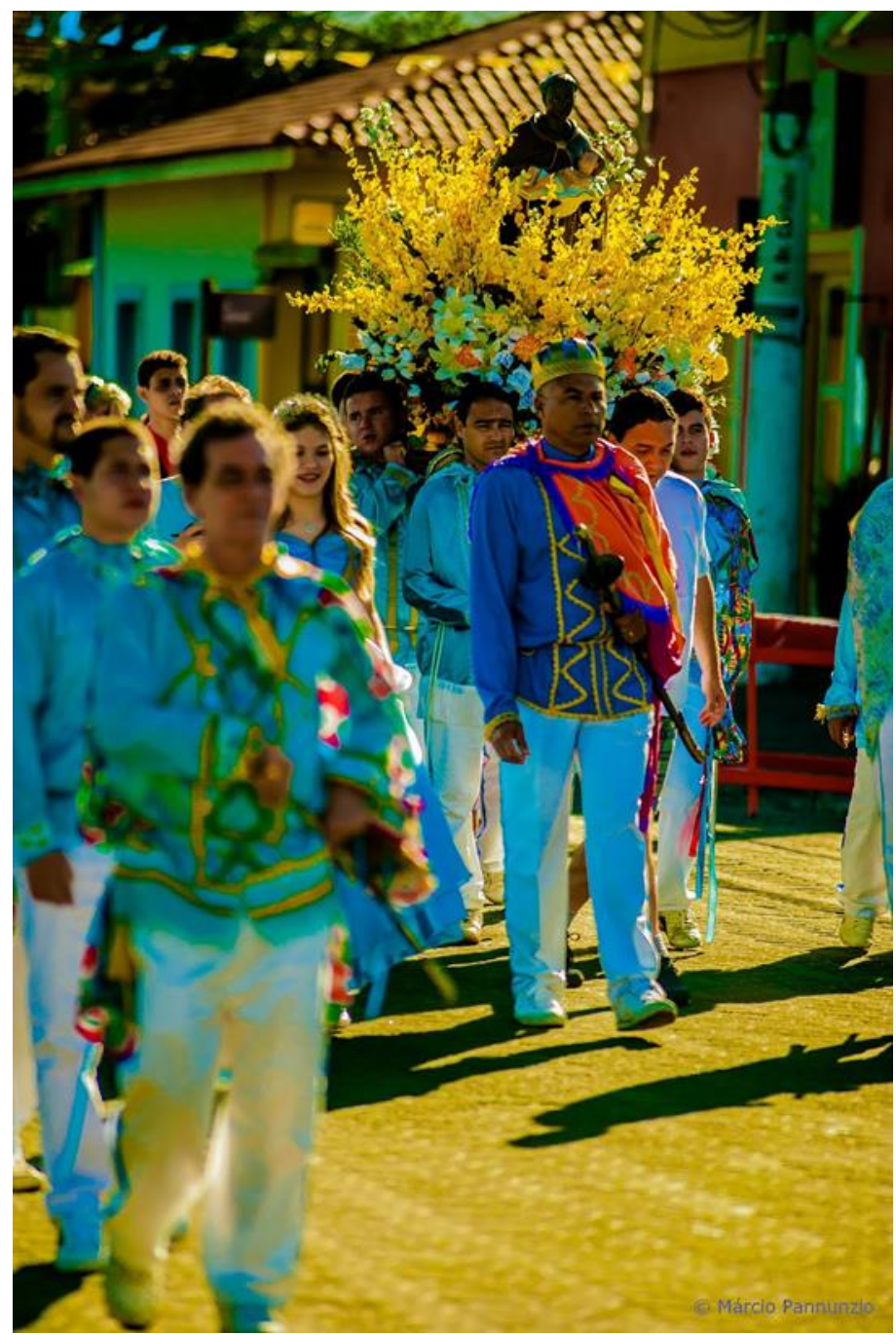

Fonte: http://www.novaimprensa.com/2016/05/foto-em-foco-congada.html. Acesso: 20.06.2016.

Nas mudanças dos trajes, revelam-se a luta desse grupo étnico-racial em Ilhabela. Assim, quando o algodão é substituído pelo cetim, o pé descalço ou as alpargatas são substituídos pelos tênis, a espada por metais baratos ou resinas, o lenço amarrado na cabeça por chapéus bordados e coloridos, os terreiros pelas ruas, as rodas e giras ao santo, as palavras africanas misturadas aos cânticos católicos, deparamo-nos com atualizações em meio às permanências.

A marimba, instrumento musical, acompanha o tempo e permanece como um elemento característico dessa manifestação da cultura africana e afro-brasileira. 
Hoje, os congueiros podem entrar na igreja, reverenciar o santo e serem igualmente reverenciados; a marimba e os atabaques os acompanham na Missa dos Congos. As mulheres e os homens associam aos trajes dos congos as estampas africanas e elementos do candomblé.

\section{Traje da Tradição - usos e significados}

Entende-se que o ato de vestir e cobrir o corpo expressa um papel importante na formação social da identidade, pois a maneira como a humanidade se veste - e isso ocorre e ocorreu em diversas épocas e culturas - influencia o modo através do qual o indivíduo se insere na sociedade.

A veste pode expressar o grupo religioso que frequenta, as ideologias políticas adotadas, o estrato social ao qual se enquadra e os agrupamentos culturais formados na busca incessante de pertencimento/ reconhecimento. Entende-se que o vestuário tornase um veículo de expressão individual e social. Assim, as vestes escolhidas pela pessoa, pelo grupo social a que pertence ou pela situação cultural em que se encontra reiteram uma ação, seja esta por meio da coesão ou coerção. Dentro desse movimento das identidades relacionais e do posicionamento social, o vestuário pode ser entendido como indumentária, pois esse é o termo utilizado para se referir ao conjunto de artefatos utilizado pelo homem para cobrir seu corpo (NOROGRANDO, 2011). E, por meio deles, encontramos elementos que fazem a mediação de tais relações e localizam os indivíduos no tempo e no espaço, também dentro de um dos movimentos da moda. ${ }^{2}$

Dito de outra forma, o ato de vestir enquanto atividade humana é antes de tudo um ato de expressar valores, de comunicar gostos pessoais e identidades, de revelar grupos de pertencimento e indagações ou mentalidade do seu tempo; apresenta o sujeito, as suas relações sociais, as suas ideias e os modos em geral. Mas também pode apresentar identidades negociadas de grupos minoritários ou excluídos da sociedade abrangente e que lutam pelo reconhecimento de seu grupo étnico-racial, como identificamos ser um dos pilares do processo de criação de identidades na reinvenção de tradição na Congada de Ilhabela.

\footnotetext{
${ }^{2} \mathrm{O}$ texto apresentado neste subtítulo, em parte, traz a noção de indumentária que adotamos no MIMo Museu da Indumentária e da Moda e dentro do que discutimos em nossos estudos sobre os trajes tanto nos museus quanto no uso cotidiano.
} 
Os trajes feitos, seja pela Dona Aurora, seja pelas costureiras das famílias dos congos ou congueiros, representam o lugar que cada um ocupa na tradição. Trajes que vestem nos dias da Festa e depois são guardados em suas casas, passando de geração a geração, quando possível. Os sapatos se desgastam, um cetim ou outro também, as fitas dos chapéus se soltam, os bordados nos mantos feitos de chita não duram tanto. A umidade das casas caiçaras não ajuda no armazenamento das vestes tradicionais. Também não há nenhum museu que faça o trabalho de acondicionamento correto. As costureiras restauram, consertam as costuras e bordados dos trajes até quando este aguentar.

Assim como as espadas se perdem, os mantos ou capas perdem o colorido vivo e são trocados. Os congos crescem e as roupas são refeitas com as referências de antes. Os chapéus são bordados de forma mais livre, sem ter um modelo tão específico, e parece ser a peça da indumentária dos congos em que mais aparecem suas individualidades. Os novos trajes recebem novos elementos, alguns tons começam a destoar, o moderno adentra a tradição, mas não chega a provocar dissidências, a fé e a resistência deste grupo são superiores ao ato do desgaste das formas, as tramas são outras e muito mais complexas.

Italiano e Viana apresentam especificidades dentro da conceituação de traje civil, e entre as categorias aparece o traje dos folguedos que seria " a indumentária usada nas festas, nos divertimentos, nas brincadeiras de caráter popular. Entram aqui os trajes folclóricos ou das festas populares cristãs, afro-brasileiras e ibéricas. ” (2015, p. 61). No entanto, ao pensar o traje do congueiro em Ilhabela, não vejo que este possa ser enquadrado dentro dessa categoria. Primeiro, porque a Congada de Ilhabela na Festa de São Benedito não é considerada folclórica pelos seus integrantes. Tanto que não se apresentam em nenhum outro lugar e nem data. As únicas alterações de datas realizadas ao longo da história dessa manifestação cultural foram negociadas entre os envolvidos, segundo relatou o congueiro Pedro Ercílio (1998):

\footnotetext{
"Primeiro a congada acontecia quando não tinha pescaria, de acordo com a lua. Depois mudou para 13 de Maio em função da libertação dos escravos. Aí todo mundo começou trabalhar durante a semana para os turistas, e não dava mais pra fazer a festa durante a semana. Foi por isso que ela é sempre
} 
no terceiro final de semana do mês de maio. Sempre, não sai daqui pra nada. A congada de São Benedito é devoção, não é folclore"

Lopes trabalha com a ideia de que as cerimônias afro-católicas eram formas de manter os "negros sob controle". Em suas palavras:

\begin{abstract}
Mas os negros, especialmente os bantos, souberam, [...] usar com sabedoria, em proveito de sua continuidade histórica, a estrutura que os brancos lhes ofereceram. Tanto assim, que, abolida em meados do século XIX a estratégia escravista da eleição do "Rei do Congo", as celebrações que a cercavam, e que eram de iniciativa dos próprios negros, permaneceram, transformando-se em autos ou danças dramáticas (LOPES, 1988, p. 150).
\end{abstract}

Verifica-se, assim, o papel da indumentária pela função e pela finalidade: seu uso, as formas de vestir e sua interatividade com o meio, um posicionar-se no mundo e, no caso, usar trajes para celebrar uma festa, um santo que foi assumido como daquele lugar, daquele grupo, como devoção e também como uma forma de manifestar uma liberdade negociada. Olhar a indumentária por esse ângulo remete ao seu valor como produto da cultura e como portadora de representações, da realidade e ou do imaginário; como reveladora de dinâmicas culturais e novas (re)produções simbólicas. 


\section{A Festa e seus agentes}

Figura 4: O Levantamento do Mastro dá início à Congada de Ilhabela. Foto:

Márcio Pannunzio.

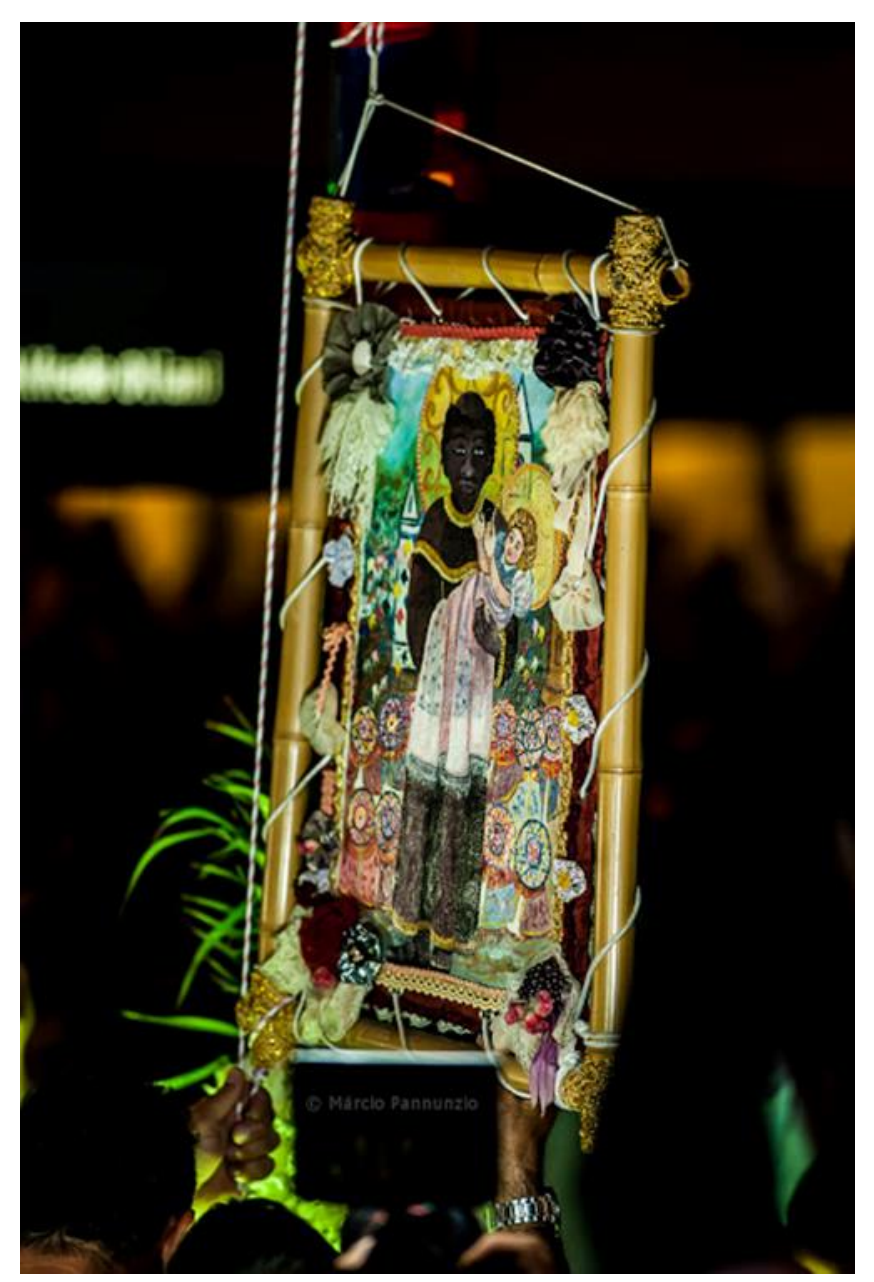

Fonte: http://www.novaimprensa.com/2016/05/foto-em-foco-congada.html. Acesso:

$$
\text { 20.06.2016. }
$$

A festa antigamente, como dizem os congueiros mais velhos, era ao longo de um ano, por um festeiro escolhido pela comunidade. O Rei tinha o respeito merecido e assim era tratado no dia-a-dia. Tudo era por conta dos congueiros. Hoje, já não é assim, falasse com tristeza e nostalgia.

O mastro que carrega a bandeira do santo é um momento bastante esperado, pois dá início às festividades, e, diríamos, que se trata de um dos momentos mágicos da Congada. Ele tem 9 metros, é recoberto de flores e carrega a imagem estampada em uma tela e recoberta de tecidos que representa a aproximação do Santo aos homens de tradição. Lá estão as cores azul e rosa, lá estão os chapéus bordados, lá está o menino 
branco carregado pelo santo negro, com os mesmos tecidos e bordados das roupas dos homens. Lá estão o santo e os negros demonstrando a recriação da identidade afrobrasileira dentro da realidade ilhabelense.

A tradição se renova. A memória emerge sempre que a Festa se realiza. Ao ouvir as histórias de uns e de outros, o pesquisador depara-se com a composição de um mosaico em que os pedacinhos (fragmentos) das lembranças de um vão se encostando aos de outros, formando uma paisagem do passado baseada no presente vivido. A lembrança é também o momento da revisão da vida e constata-se que os objetos - entre eles, as roupas - apoiam o lembrar. Desta forma, acredita-se que, ao observar e conhecer os motivos que levaram à criação e ao uso tradicional de determinados trajes, tem-se maior possibilidade de adentrarmos outros sentidos da festa popular e relacionar, portanto, o design, a moda e a cultura. O problema que se coloca é que pouco se conta sobre as origens dos trajes, seus significados: por que o azul, por que o rosa etc.?

Figura 5 e 6: Momentos da Congada que revelam a devoção. Os trajes revelam o lugar de cada um na manifestação cultural. Os chapéus são peças que os individualizam. Fotos de Douglas

Lopez

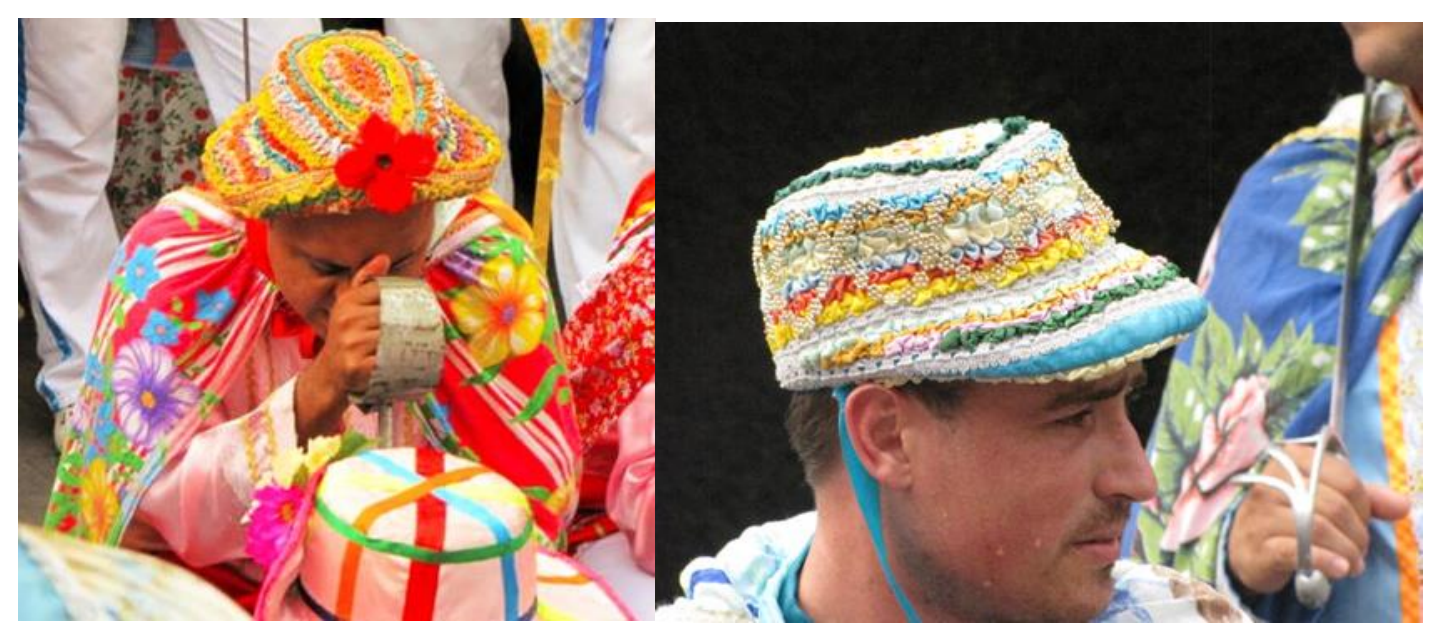

Fonte: Arquivo Pessoal. Maio de 2014.

Todas as explicações retornam ao fato de ser "por tradição" e assim o é, assim fica sendo. Faz sentido para eles, ficam as dúvidas para nós, no intuito de continuarmos refletindo sobre os trajes em manifestações da cultura de rua. Ainda mais ao se tratar de um grupo que resiste ao descaso social, que luta contra a segregação racial, que se apoia na tradição, na força da devoção para continuar unido. Como dito anteriormente, o traje 
do congo ilhabelense ganha os sentidos e significados da festa, pois, sem a festa, a roupa não teria o menor sentido e, sem a roupa, não haveria o reconhecimento do papel de cada um na festa. Por isso guardar o traje, por isso mantê-lo e reproduzi-lo ano a ano.

A tradição oral e a resistência do grupo étnico-racial negro de Ilhabela foram de extrema importância para a continuidade da Congada. Unir a essa manifestação da cultura afrodescendente a devoção ao São Benedito, por meio da criação de um mito do Benedito ilhabelense, fez com que esse grupo encontrasse mais força para sua inserção naquela sociedade. A memória coletiva, no caso, atua como fortalecedora dos laços desse grupo social e escancara o sincretismo religioso daquele lugar. Os congos de Ilhabela, com seus trajes aparentemente simples, são uma das manifestações culturais que mais revelam as contribuições culturais do africano e do afrodescendente na vida caiçara.

Pollak nos esclarece que, quando se tem uma escuta, podem emergir lembranças que rompem silêncios e revelam situações diversas, isto porque "há uma permanente interação entre o vivido e o aprendido, o vivido e o transmitido. E essas constatações se aplicam a toda forma de memória, individual e coletiva, familiar, nacional e de pequenos grupos" (1989, p. 9). Percebe-se que “o que está em jogo na memória é também o sentido da identidade individual e do grupo" (ibidem, p. 10).

No caso da Congada, não basta observar para compreender sua simbologia, seus sentidos dentro da comunidade envolvida; foi preciso ouvir seus protagonistas. Eles tornaram-se informantes na pesquisa e por meio da observação participante e dos diálogos abriu-se um novo horizonte para entender outras nuances dessa festa e dessa gente. Nesse sentido, entende-se que as narrativas serviram para historiar o cotidiano vivido, levando-se em conta até onde o raio da memória conseguiu alcançar. Isso foi feito na pesquisa e as próprias lembranças da pesquisadora são rememoradas neste artigo para voltar no tempo da memória e pensar o sentido dos trajes, algo a que não se propunha anteriormente, mas para o qual se volta o interesse atualmente.

Entre as narrativas, estabelece-se a relação entre o narrador e a substância do que se conta, assim como podemos incluir a "coisa" narrada, em um movimento entre o objeto da memória coletiva e a memória do objeto. Aliás, um apoia a lembrança do outro, e assim é com o traje. Muitas vezes surge uma lamentação: “Os jovens hoje não 
cuidam das roupas da congada. A gente compra o tênis branco para usar nos dias da festa e eles usam para sair com os amigos, para ir na escola e, quando chega o outro ano, tem que comprar tudo de novo. Não respeitam a tradição" (Congueiro, 1999).

O entorno (ou substância) de toda memória é o tempo presente, o que se vive, o que se lembra, o que se viveu que não pode mais ser vivido, o que se mantém, o que se perdeu, o que se produziu, o que vestiu, o que festejou, como e por que.

\begin{abstract}
A narrativa [...] é ela própria, num certo sentido, uma forma artesanal de comunicação. Ela não está interessada em transmitir o 'puro em si' da coisa narrada como uma informação ou um relatório. Ela mergulha a coisa na vida do narrador para em seguida retirá-la dele. [...] Assim, seus vestígios estão presentes de muitas maneiras nas coisas narradas, seja na qualidade de quem as viveu, seja na qualidade de quem as relata. (BENJAMIN, 1985, p. 205)
\end{abstract}

Poderíamos dizer que os vestígios a que Benjamin se refere podem ser relacionados ao que os objetos carregam de memória. Ou seja, o artefato foi pensado, produzido, reproduzido, assumido. Esse processo imenso e intenso de fazer uma ideia transformar-se em produto e deste ser usado de modos diversos faz com que ele (objeto) contenha histórias - história de seu processo de idealização e produção; história dos valores que lhe foram agregados para serem desejados e comprados; histórias de seu uso e de quem usa. Quantas lembranças um único traje pode conter? Os objetos permeiam toda a existência humana e os trajes de tradição preexistem e continuam além do momento da festa, pois os sentidos/sentimentos que carregam são diversos.

Como diz Brandão,

através do rito, o homem se incorpora ao mito, beneficiando-se de todas as forças e energias que jorraram nas origens. A ação ritual realiza no imediato uma transcendência vivida. O rito toma, nesse caso, 'o sentido de uma ação essencial e primordial através da referência que se estabelece do profano ao sagrado'. Em resumo: o rito é a práxis do mito. É o mito em ação. O mito rememora, o rito comemora. (1986, p. 39)

Por fim, quando deparo com a insistência dos congueiros em dizer que a congada é religião e por isso deve permanecer viva, também percebo uma resistência a tudo o que pode identificá-los fora desse contexto. A religião para eles parece firmar e 
reafirmar o grupo e o espaço social que ocupam em território ilhabelense - um espaço que está entre o sagrado e o profano, mas também o lugar do negro em uma sociedade que se quer e se sente branca.

Nas palavras de Montero:

\begin{abstract}
Ora, as identidades não resultam espontaneamente do pertencimento empírico a uma cultura. Seriam, ao contrário, consequência de um processo simbólico de autodesignação de traços culturais - mesmo daqueles que podem ser fisicamente aferidos como ausentes - que retira sua inspiração de um repertório cultural disponível (próprio ou alheio). Desse modo, a continuidade de uma etnia dependerá da capacidade de um determinado grupo de manter simbolicamente suas fronteiras de diferenciação, ou, dito de outra maneira, de sua capacidade de manter uma codificação permanentemente renovada das diferenças culturais que o distinguem dos grupos vizinhos (1997, p. 62-3).
\end{abstract}

Assim, as ruas, o santo, os homens e as mulheres, os trajes, a moda remontam a história de um grupo étnico-racial em uma sociedade que se diz plural, mas permanece excludente. Tempos para se refletir, tempos para mudar. Pensando a relação intrínseca entre o design e a cultura, e entendendo o design como uma atividade humana por excelência, nos deparamos com o reflexo em nossos espelhos, mas o quanto ainda precisamos ampliar nossa ótica.

\title{
Artigo recebido em Maio de 2016. Aprovado em Junho de 2016 DOl:http://dx.doi.org/105965/1982615x09182016057
}

\section{Referências}

BRANDÃO, Carlos Rodrigues. A cultura na rua. $2^{\mathrm{a}}$. Edição. Campinas, SP: Papirus, 2001.

GAUDITANO, Rosa; TIRAPELI, Percival. Festas de Fé. São Paulo: Metalivros, 2003.

GONÇALVES, José Reginaldo Santos. Antropologia dos objetos: coleções, museus e patrimônio. Rio de Janeiro: Coleção Museu, Memória e Cidadania, Minc/Iphan/DMCC, 2007. 
HALBWACHS, Maurice. A memória coletiva. São Paulo: Vértice, 1990.

HOBSBAWM, Eric \& RANGER, Terence. A invenção das tradições. Rio de Janeiro: Paz e Terra, 1984.

ITALIANO, Isabel et al. Para vestir a cena contemporânea: moldes e moda no Brasil do século XIX. São Paulo: Estação das Letras e Cores, 2015.

LOPES, Nei. Bantos, malês e identidade negra. Rio de Janeiro: Forense Universitária, 1988.

MERLO, Márcia. Entre o mar e a mata: a memória afro-brasileira. São Sebastião, Ilhabela e Ubatuba. São Paulo: FAPESP: EDUC, 2005.

Memória de Ilhabela: faces ocultas, vozes no ar. São Paulo: EDUC:

FAPESP, 2000.

NOROGRANDO, Rafaela. Como é formado o patrimônio cultural. Estudo museológico em Portugal na temática Traje/Moda, dissertação de mestrado em Antropologia Social e Cultural, orientada por Nuno Porto e Kathia Castilho, Departamento de Ciências da Vida, Universidade de Coimbra, Coimbra, Portugal, 2011.

BENJAMIN, Walter. "O narrador. Considerações sobre a obra de Nikolai Leskov". In: Magia e técnica, arte e política: ensaios sobre literatura e história da cultura. Tradução de Sérgio Paulo Rouanet. São Paulo: Brasiliense, 1994. (Obras Escolhidas; v. 1)

MERLO, Márcia. Congada de Ilhabela: o santo, o homem, a festa, o negro e o lugar. IN: Revista Ângulo 127, Set./Dez., 2011, p. 46-53

MONTERO, Paula. "Globalização, identidade e diferença". In: Novos Estudos CEBRAP, nº 49. São Paulo: Cebrap, 1997, p. 47- 64.

POLLAK, Michael. "Memória, esquecimento, silêncio". In: Estudos Históricos Memória, Rio de Janeiro, v. 2, n. 3, 1989, pp. 3-15. 
. "Memória e identidade social". In: Estudos Históricos - Teoria e História, Rio de Janeiro, Vol. 5, nº 10, 1992, pp. 200-212.

http://culturadigital.br/construindoosom/oficinas/marimba-de-arco/ilhabela_congada3/ Acesso: 30.05.2016.

http://www.ilhabela.sp.gov.br/ilha/imagens_conteudo/userfiles/images/ Acesso: 30.05.2016.

http://www.novaimprensa.com/2016/05/foto-em-foco-congada-parte-iii-o.html 